\title{
Períodos de Interferência das Plantas Daninhas na Cultura da CANA-DE-AÇÚCAR. III - CAPIM-BRAgUIÁRIA (Brachiaria decumbens) E CAPIM-Colonião (Panicum maximum) ${ }^{1}$
}

\author{
Interference Periods of Weeds in the Sugarcane Crop. III-Brachiaria decumbens and \\ Panicum maximum
}

\begin{abstract}
KUVA, M.A. ${ }^{2}$, GRAVENA, R. ${ }^{3}$, PITELLI, R.A. ${ }^{4}$, CHRISTOFFOLETI, P.J. ${ }^{5}$ e ALVES, P.L.C.A. ${ }^{6}$
RESUMO - Um experimento foi conduzido em São João da Boa Vista-SP, com o objetivo de determinar o período anterior à interferência (PAI) e o período total de prevenção à interferência (PTPI) das plantas daninhas na cultura da cana-de-açúcar. A cana foi plantada em abril de 1995, na época de plantio caracterizada por maior deficiência hídrica. A comunidade infestante presente foi variada, sendo Brachiaria decumbens e Panicum maximum as espécies mais importantes. Essa comunidade tendeu a apresentar acúmulo crescente de matéria seca durante todo o período de avaliação e reduziu em até $40 \%$ a produtividade de colmos da cana-de-açúcar. A cultura conviveu com a comunidade infestante até 74 dias após o plantio, sem sofrer redução significativa na produtividade (PAI). O período mínimo de controle para garantir a produtividade foi de 127 DAP (PTPI). Dessa forma, o controle das plantas daninhas foi crítico no período compreendido entre 74 e 127 dias após o plantio.
\end{abstract}

Palavras-chave: Saccharum spp., planta daninha, competição.

\begin{abstract}
A field trial was carried out in São João da Boa Vista, SP, to determine the critical time of weed removal and the critical weed-free period in sugarcane. The crop was planted on April 1995, at the beginning of the dry season. The species composing the weed community varied during the growing season. However, Brachiaria decumbens and Panicum maximum were the most important ones. Dry matter accumulated by the weed community increased during the entire period. Weed interference in sugarcane caused $40 \%$ of yield loss. Sugarcane grew along with the weed community up to 74 days after planting, without significant yield loss (critical time of weed removal). A minimal weed-free period of 127 days after planting was required to guarantee the sugarcane productivity (critical weed-free period). The critical period for weed control was between 74 and 127 days after planting.
\end{abstract}

Key words: Saccharum spp., weed, competition.

\section{INTRODUÇÃO}

Dentre os fatores bióticos, as plantas daninhas são um dos principais componentes do agroecossistema da cana-de-açúcar que interferem no desenvolvimento e na produtividade desta cultura. A presença dessas plantas pode interferir no processo produtivo da cana-deaçúcar, competindo pelos recursos do meio, principalmente água, luz e nutrientes, liberando substâncias alelopáticas, atuando como hospedeiro de pragas e doenças comuns à cultura e interferindo nas práticas de colheita (Pitelli, 1985). A ocorrência de um ou mais

1 Recebido para publicação em 15.8.2002 e na forma revisada em 2.4.2003.

Parte da dissertação de mestrado do primeiro autor apresentada à ESALQ/USP.

2 Pós-graduando do curso de Produção Vegetal (Doutorado), Dep. de Biologia Aplicada à Agropecuária - FCAV/UNESP. ${ }^{3}$ Pósgraduando do curso de Fitotecnia (Doutorado) - ESALQ/USP. ${ }^{4}$ Prof. Titular, Dep. de Biologia Aplicada à Agropecuária FCAV/UNESP. ${ }^{5}$ Prof. Associado, Dep. de Produção Vegetal - ESALQ/USP. ${ }^{6}$ Prof. Assistente, Dep. de Biologia Aplicada à Agropecuária - FCAV/UNESP. 
desses componentes de interferência poderá reduzir a quantidade de colmos colhidos e diminuir o número de cortes economicamente viáveis (Lorenzi, 1988).

O grau de interferência entre as plantas cultivadas e as plantas daninhas depende de fatores relacionados à comunidade infestante (composição específica, densidade e distribuição) e à própria cultura (gênero, espécie ou cultivar, espaçamento entre sulcos e densidade de semeadura). Depende também da duração do período de convivência, da época em que este período ocorre que é modificado pelas condições edáficas e climáticas e pelos tratos culturais (Pitelli, 1985).

Estudos sobre períodos críticos de interferência entre plantas daninhas e a cultura da cana-de-açúcar foram realizados por Rolim \& Christoffoleti (1982), Graciano \& Ramalho (1983), Graciano \& Barbosa (1986), Graciano (1989), Constantin (1993), Coleti et al. (1997) e Kuva et al. (2000, 2001). Entretanto, as constantes mudanças no sistema de produção da cana-de-açúcar, com a adoção de novos espaçamentos e variedades e variações nas condições de cultivo, exigem a realização de estudos de períodos de interferência com maior freqüência e em diferentes locais e épocas do ano, visando adequar as práticas de manejo de plantas daninhas, reduzir as perdas e reduzir o impacto ao meio ambiente provocado pelo uso inadequado de medidas de controle.

O objetivo deste trabalho foi determinar o período anterior à interferência, o período total de prevenção à interferência (PTPI) e o período crítico da prevenção da interferência (PCPI) das plantas daninhas na produtividade da cultura de cana-de-açúcar plantada ao final da época chuvosa.

\section{MATERIAL E MÉTODOS}

O experimento foi conduzido no município de São João da Boa Vista-SP, em área de reforma de canavial (cana-planta) da Usina São João. O solo da área é classificado como Latossolo Vermelho-Amarelo e apresentava $\mathrm{pH}$ $\left(\mathrm{CaCl}_{2}\right)$ de 5,5; 39,8 $\mathrm{g} \mathrm{dm}^{-3}$ de matéria orgânica; e teores de $\mathrm{P}=19,0 ; \mathrm{K}=0,52 ; \mathrm{Ca}^{+2}=$ 4,$62 ; \mathrm{Mg}^{+2}=1,22 \mathrm{e} \mathrm{H}+\mathrm{Al}=4,46$, expressos em $\mathrm{mmol} \mathrm{dm}^{-3}$.
A variedade de cana-de-açúcar RB835089 foi plantada no dia 25 de abril de 1995, numa densidade de dois colmos lado a lado no sulco, com linhas de plantio espaçadas de 1,35 m. A adubação foi efetuada no sulco, com $700 \mathrm{~kg} \mathrm{ha}^{1}$ da fórmula 03-09-13 (N-P-K). A colheita foi realizada 15 meses após o plantio.

Os tratamentos experimentais foram constituídos por nove períodos crescentes de convivência ou controle das plantas daninhas com a cultura, em relação à emergência da canade-açúcar. Os tratamentos foram separados em dois grupos: M (Mato), para os períodos iniciais de convivência com as plantas daninhas, e L (Limpo), para os períodos iniciais de controle. Os períodos de convivência ou controle foram de 0-14, 0-28, 0-42, 0-63, 0-84, 0-105, 0-126, 0-147 e 0-450 (colheita da cana) dias após o plantio da cana-de-açúcar.

Foi adotado o delineamento experimental de blocos casualizados, com quatro repetições. As parcelas experimentais foram compostas por cinco linhas de plantio de cana-de-açúcar, com 10 metros de comprimento. As avaliações foram realizadas na área útil das parcelas, considerando como bordadura uma linha de plantio de cada lado da parcela e um metro de cada extremidade das três linhas centrais.

Nas parcelas destinadas à convivência inicial da cultura com a comunidade infestante (tratamentos do grupo M), as amostragens das plantas daninhas foram realizadas ao final do período estipulado. Nestas amostragens foram utilizados quadros vazados de ferro com $0,5 \mathrm{~m}$ de lado e área interna de $0,25 \mathrm{~m}^{2}$, que foram lançados oito vezes, ao acaso, na área útil das parcelas. As plantas contidas na área amostral foram coletadas e separadas por espécie, determinando-se a densidade e a massa de matéria seca. A amostragem das plantas daninhas nas parcelas destinadas aos períodos crescentes de controle da comunidade infestante (tratamentos do grupo L) foi realizada na época da colheita da cana-de-açúcar. Nesse caso, foram utilizados quadros vazados de ferro com 1,0 $\mathrm{m}^{2}$ de área interna. As plantas que se encontravam dentro do quadro foram coletadas, determinando-se a massa total de matéria seca da comunidade infestante.

A remoção das plantas daninhas ao final de cada período de convivência inicial, bem 
como a manutenção destas parcelas livre da presença delas até o fechamento das entrelinhas pela cultura, foi realizada mediante capina manual. Os períodos crescentes de controle também foram obtidos com freqüentes operações de capina manual, que eram interrompidas à medida que se atingia o final de cada período.

A cultura foi colhida no sistema de corte manual de cana queimada e o rendimento foi quantificado pelo peso do total de colmos produzidos na área útil de cada parcela, utilizando um dinamômetro acoplado entre a garra hidráulica e o "braço" da carregadeira. Os dados obtidos foram extrapolados para toneladas de cana por hectare.

Os dados referentes à comunidade infestante, como densidade e massa seca acumulada, foram extrapolados para número de plantas e gramas de matéria seca por metro quadrado, respectivamente.

Os dados de rendimento da cultura foram processados separadamente dentro de cada grupo (L ou M), sendo submetidos à análise de regressão pelo modelo sigmoidal de Boltzman, adaptado por Kuva et al. (2000):

$$
Y=\frac{\left(A_{1}-A_{2}\right)}{1+e^{\left(X-X_{0}\right) / d x}}+A_{2}
$$

em que, $Y$ é a produção de cana-de-açúcar, em t ha' ${ }^{-1}$, obtida conforme os períodos de controle ou de convivência; $X$, o limite superior do período de controle ou de convivência (dias); $A_{1}$, a produção máxima, em $\mathrm{t} \mathrm{ha}{ }^{-1}$, obtida nas parcelas mantidas no limpo durante todo o ciclo; $A_{2}$, a produção mínima, em t ha-1 ${ }^{-1}$ obtida nas parcelas mantidas no mato durante todo o ciclo; $\left(A_{1}-A_{2}\right)$, a perda de produção, em $t$ ha $^{-1}$; $X_{0}$ o limite superior do período de controle ou de convivência, que corresponde ao valor intermediário entre a produção máxima e a mínima; e dx, o parâmetro que indica a velocidade de perda ou ganho de produção (tangente no ponto $X_{0}$ ).

Também foram realizados estudos de regressão linear entre os dados de rendimento da cana e de matéria seca acumulada pelas plantas de capim-braquiária (Brachiaria decumbens) e capim-colonião (Panicum maximum).

\section{RESULTADOS E DISCUSSÃO}

A comunidade infestante foi heterogênea, sendo constatada a presença de mais de 13 espécies de plantas daninhas na maioria dos levantamentos realizados. Dentre as mais numerosas, destacaram-se: erva-palha (Blainvillea rhomboidea), guanxumas (Sida spp.), corda-de-viola (Ipomoea acuminata), mentrasto (Ageratum conyzoides) e cheirosa (Hyptis suaveolens). Contudo, as principais plantas daninhas existentes nesse agroecossistema e que sabidamente causam danos à cultura foram o capim-braquiária $(B$. decumbens, BRADC) e o capim-colonião (P. maximum, PANMA).

A predominância na comunidade infestante foi de espécies de plantas daninhas dicotiledôneas, que se apresentaram numa densidade variando entre 50 e 100 plantas $\mathrm{m}^{-2}$, dos 14 aos 126 dias após o plantio (DAP). A partir dos 126 DAP a densidade teve grande aumento, culminando em mais de 225 plantas $\mathrm{m}^{-2}$ (Figura 1). Houve relação direta entre a germinação das plantas daninhas e a incidência das precipitações pluviais (Figura 2). A precipitação acumulada de $46 \mathrm{~mm}$, que ocorreu no período de 0 a 14 DAP, proporcionou condições ao processo de germinação das sementes, resultando numa comunidade infestante com densidade pouco superior a 100 plântulas $\mathrm{m}^{-2}$, das quais seis eram de capim-braquiária. O período seco que se seguiu - $5 \mathrm{~mm}$ dos 14 aos 42 DAP reduziu praticamente pela metade a densidade de plantas aos 42 DAP. A repetição de um novo período de chuva (56 mm dos 42 aos 84 DAP) provocou nova oscilação na densidade total de plantas daninhas. Com o reinício das chuvas de primavera houve germinação de grande quantidade de sementes, principalmente de guanxuma e erva-palha. A densidade de plantas daninhas, que aos 126 DAP era de 45 plantas $\mathrm{m}^{2}$, passou para 231 plantas $\mathrm{m}^{-2}$ aos 147 DAP.

O capim-braquiária, embora em baixa densidade quando comparado com as demais espécies, apresentou comportamento semelhante, em função do tempo e das precipitações pluviais, culminando em quase 10 plantas $\mathrm{m}^{-2}$, aos 147 DAP. A presença de capim-colonião foi verificada a partir dos 42 DAP, sendo a maior densidade encontrada de 4,83 plantas $\mathrm{m}^{-2}$, aos

Planta Daninha, Viçosa-MG, v.21, n.1, p.37-44, 2003 
63 DAP. Destas, no entanto, apenas 2 plantas $\mathrm{m}^{-2}$ sobreviveram à interferência imposta pelas demais espécies presentes e pela própria cultura e se mantiveram vivas até os 147 DAP (Figura 1).

O acúmulo de matéria seca pela comunidade infestante e pelas plantas de capimbraquiária em função do aumento dos períodos de convivência ocorreu de maneira crescente (Figura 3), independentemente das oscilações da precipitação pluviométrica. Isso significa que as plantas que sobreviveram à competição por água durante o período sem chuva conseguiram se desenvolver. O capim-braquiária, que, em relação à densidade, respondeu por apenas $4 \%$ do total, em termos de massa seca, representou $45 \%$ do total aos 147 DAP. O aumento na massa seca acumulada por esta espécie acompanhou a tendência de aumento da comunidade infestante total. A massa seca acumulada pelo capim-colonião chegou a responder por $45 \%$ da massa acumulada pela comunidade infestante quando a convivência com a cana ocorreu por 126 dias. Dos 126 aos 147 DAP houve grande aumento na massa seca acumulada pela comunidade infestante, passando de 96 para 250 g M.S. m ${ }^{-2}$ (gramas de matéria seca por metro quadrado). Entretanto, esse aumento ocorreu em função das demais espécies presentes, principalmente do capim-braquiária, uma vez que a massa acumulada pelas plantas de capim-colonião se manteve praticamente constante nesse período (Figura 3).

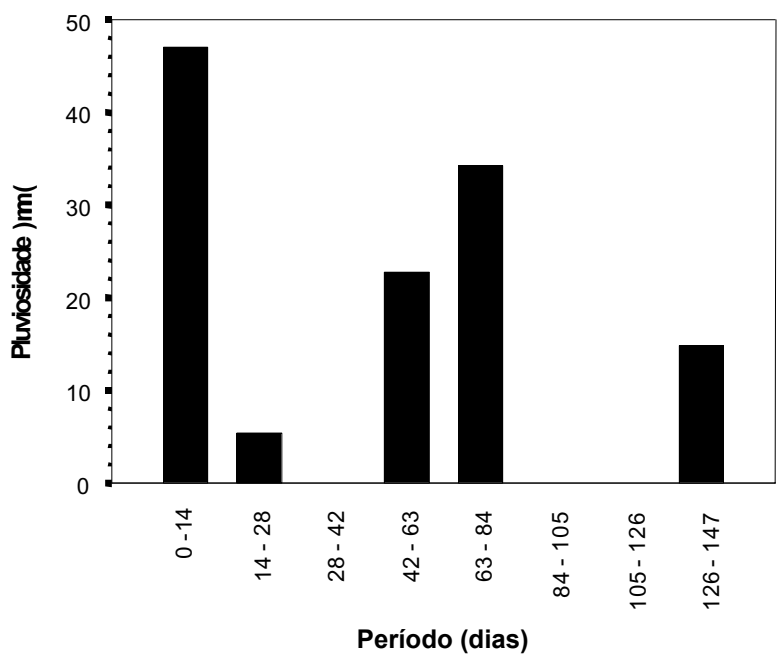

Figura 2 - Precipitação pluvial durante os períodos de controle ou de convivência estudados. São João da Boa Vista-SP, 1995.

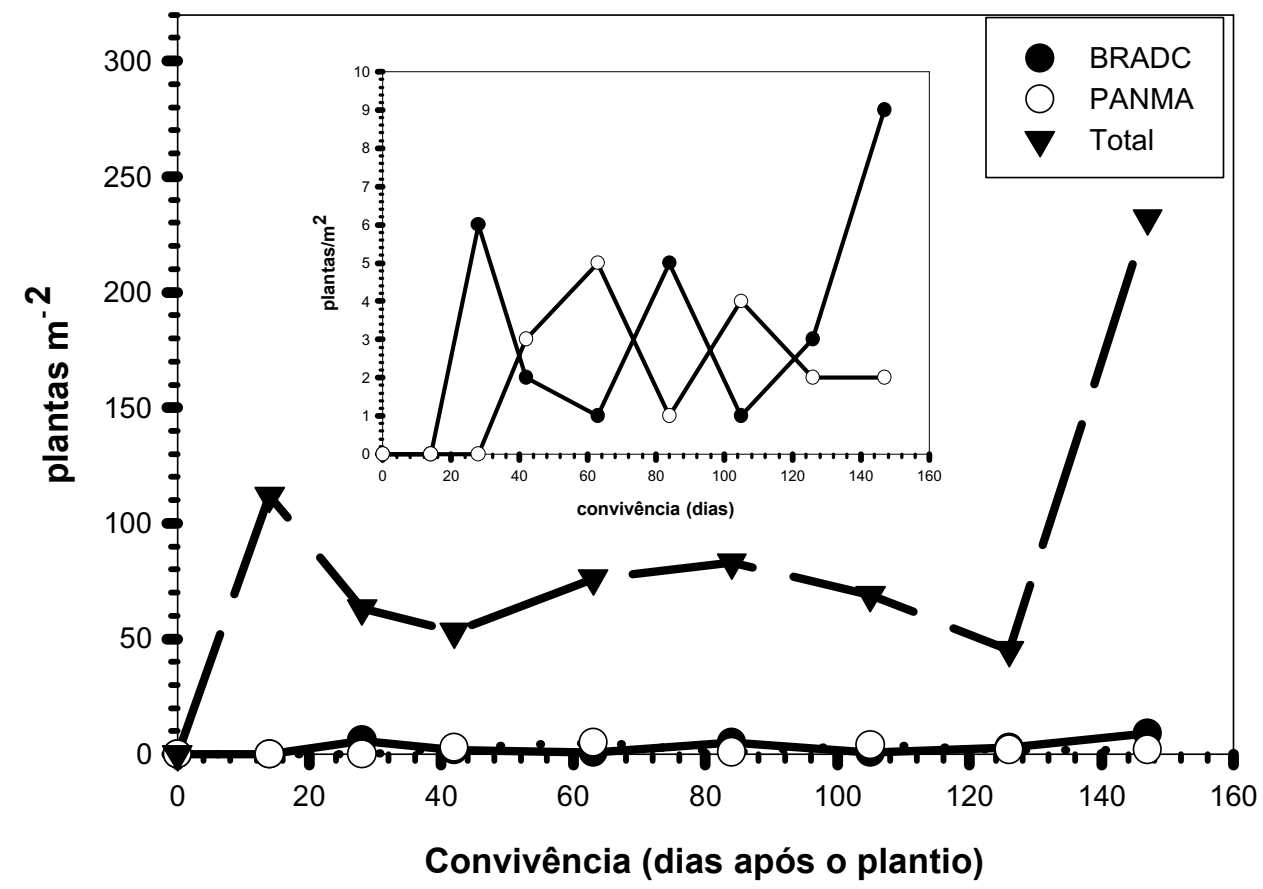

Figura 1 - Densidade de plantas daninhas, com destaque para o capim-braquiária (BRADC) e o capim-colonião (PANMA), no gráfico subscrito, ao final dos períodos de convivência com a cana-de-açúcar. São João da Boa Vista-SP, 1995. 


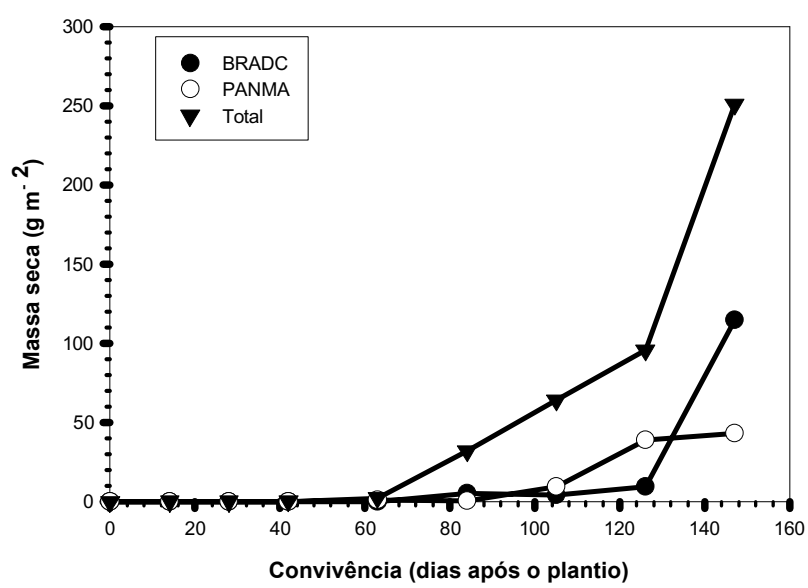

Figura 3 - Massa seca de plantas daninhas ao final de cada período de convivência com a cana-de-açúcar. São João da Boa Vista-SP, 1995.

Por ocasião da colheita da cana-de-açúcar, a ausência de controle durante todo o ciclo dessa cultura resultou num acúmulo de $700 \mathrm{~g}$ M.S. $\mathrm{m}^{-2}$ (Figura 4). As principais plantas encontradas nessa amostragem foram capimbraquiária, capim-colonião, guanxumas e ervapalha. Com o controle e aumento gradativo dos períodos abrangidos por ele, constatou-se redução no acúmulo de matéria seca pela comunidade infestante. As plantas daninhas que emergiram após o período de 84 DAP de controle até a colheita da cana-de-açúcar foram incapazes de produzir grandes quantidades de matéria seca.

Tendo em vista a época em que foi desenvolvido o experimento, o crescimento inicial da cultura e das plantas daninhas ocorreu nos meses em que há deficiência hídrica, podendo ter havido intensa competição por água. Com o reinício das chuvas, na primavera, a cultura e a comunidade infestante aceleraram o desenvolvimento, incrementando a competição por nutrientes. Em casa de vegetação, Bianco et al. (2000) observaram que uma única planta de capim-braquiária, irrigada com solução nutritiva completa, acumulou, aos 90 dias após a emergência, 11,55 $\mathrm{g} \mathrm{kg}^{-1}$ de N; 1,49 $\mathrm{g} \mathrm{kg}^{-1}$ de P; $24,67 \mathrm{~g} \mathrm{~kg}^{-1}$ de K; 4,25 $\mathrm{g} \mathrm{kg}^{-1}$ de Ca; 3,47 $\mathrm{g} \mathrm{kg}^{1}$ de Mg; e 15,75 $\mathrm{g} \mathrm{kg}^{-1}$ de S. Pellegrini (2000) observaram que uma única planta de capimcolonião acumulou, após 90 dias de desenvolvimento, irrigada com solução nutritiva completa, 19,73 $\mathrm{g} \mathrm{kg}^{-1}$ de $\mathrm{N} ; 1,50 \mathrm{~g} \mathrm{~kg}^{-1}$ de $\mathrm{P}$;

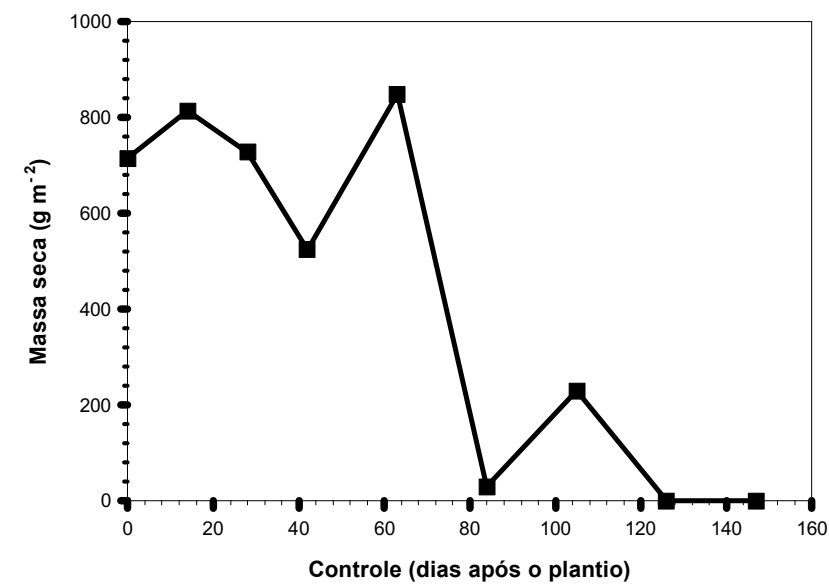

Figura 4 - Massa seca acumulada pela comunidade infestante quando submetida a diferentes períodos de controle. São João da Boa Vista-SP, 1995.

$18,05 \mathrm{gkg}^{-1}$ de $\mathrm{K} ; 5,8 \mathrm{~g} \mathrm{~kg}^{-1}$ de Ca; e $3,38 \mathrm{~g} \mathrm{~kg}^{-1}$ de $\mathrm{Mg}$. Por causa do porte que alcança, baixas densidades desta espécie podem trazer grandes prejuízos, seja pela interferência ou pelo enriquecimento do banco de sementes. Bozán \& Rey (1977) concluíram que, em apenas um ciclo vegetativo, uma única planta de capim-colonião produziu 127.350 sementes.

A representação gráfica e os parâmetros da equação sigmoidal de Boltzman obtidos para regressão dos dados de rendimento, em função dos períodos de convivência e controle das plantas daninhas, estão mostrados na Figura 5 e na Tabela 1, respectivamente. A ausência de controle durante todo o ciclo da cana-de-açúcar (da emergência da cultura ao corte) resultou em $40 \%$ de redução de produtividade, quando comparado ao obtido na ausência total de plantas daninhas. O rendimento de $141 \mathrm{t} \mathrm{ha}^{-1}$, obtido no tratamento com controle o ciclo todo, caiu para 103 e $74 \mathrm{t} \mathrm{ha}^{-1}$ quando a cultura foi mantida em convivência com as plantas daninhas por 147 dias e até a colheita, respectivamente. Admitindo perda máxima de $5 \%$ na produtividade, a cana-de-açúcar passou a ser afetada negativamente a partir de 74 dias de convivência (Tabela 2). Por outro lado, foi necessário controle da comunidade infestante por 127 dias para que a produção ficasse, no máximo, $5 \%$ abaixo da produção máxima (Figura 5). Assim, qualquer método de controle adotado, desde que imposto antes dos 74 DAP e com abrangência (efeito residual) de até pelo 
menos 127 DAP, seria suficiente para garantir rendimento aceitável.

A Tabela 2 apresenta a estimativa dos valores do limite superior do PAI e do PTPI em função da tolerância de redução de 2 e $10 \%$ na produtividade da cana-de-açúcar. Tolerando

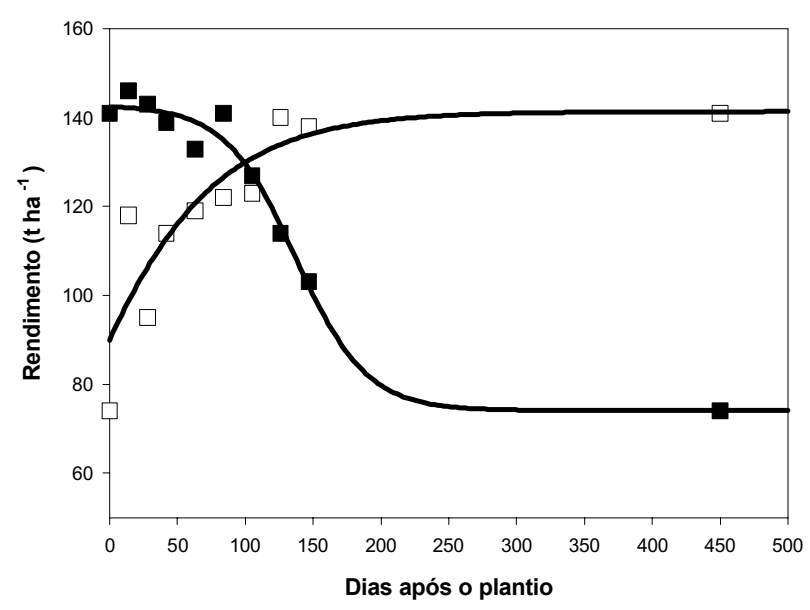

Figura 5 - Rendimento de colmos de cana-de-açúcar em função dos períodos de controle e convivência com as plantas daninhas. São João da Boa Vista-SP,1995.

Tabela 1 - Parâmetros da equação sigmoidal de Boltzman obtidos com a análise dos dados de rendimento de canade-açúcar. São João da Boa Vista-SP, 1995

\begin{tabular}{|c|c|c|}
\hline Parâmetro & Convivência & Controle \\
\hline $\mathrm{A}_{1}$ & 74,0712 & $-57,146$ \\
$\mathrm{~A}_{2}$ & 142,799 & 141,378 \\
$\mathrm{x}_{0}$ & 137,323 & $-60,1461$ \\
$\mathrm{dx}$ & $-25,9855$ & 57,2997 \\
\hline $\mathrm{r}^{2}$ & 0,979 & 0,776 \\
\hline
\end{tabular}

Tabela 2 - Variação do período anterior à interferência e do período total de prevenção à interferência em função das porcentagens de redução de rendimento toleradas. São João da Boa Vista-SP, 1995

\begin{tabular}{|l|c|c|c|c|}
\hline \multirow{2}{*}{ Período } & \multicolumn{4}{|c|}{ Porcentagem de redução } \\
\cline { 2 - 5 } & $2 \%$ & $5 \%$ & $10 \%$ & $2-10 \%$ \\
\hline $\begin{array}{l}\text { Período anterior à } \\
\text { interferência (PAI) }\end{array}$ & $0-58$ & $0-74$ & $0-106$ & 48 dias \\
\hline $\begin{array}{l}\text { Período total de } \\
\text { prevenção à } \\
\text { interferência (PTPI) }\end{array}$ & $0-186$ & $0-127$ & $0-86$ & 100 dias \\
\hline
\end{tabular}

$10 \%$ de redução na produtividade, o PAI foi de zero aos 106 dias e o PTPI foi de zero aos 86 dias. Reduzindo os níveis de tolerância para $2 \%$ o PAI passou para 58 dias e o PTPI para 186 dias. Para que as reduções de produtividade da cana-de-açúcar passassem de 2 para $10 \%$ foi necessário acréscimo de 48 dias no período de convivência, e para aumentar a produtividade de 90 para $98 \%$ foi necessário acréscimo de 100 dias no período de controle.

Os resultados obtidos em estudos de períodos críticos de competição podem indicar duas situações distintas nas relações entre a canade-açúcar e as plantas daninhas. O entendimento e a separação destas situações são de extrema importância quando se determinam a intensidade e a duração do método de controle a ser adotado. Segundo Pitelli (1985), quando o limite superior do período total de prevenção da interferência (PTPI) é muito maior que o do período anterior à interferência (PAI), são necessárias medidas de controle de plantas daninhas capazes de proporcionar extensos períodos residuais. Por outro lado, quando o limite superior do PTPI for igual ou menor que o do PAI, qualquer medida de controle, mesmo que desprovido de longos períodos residuais, é suficiente.

Kuva et al. (2001), em experimento conduzido durante a mesma época do ano, numa área predominantemente infestada por capimbraquiária, obtiveram resultados próximos, ou seja, um período crítico de prevenção à interferência (PCPI) iniciando-se aos 89 dias após o plantio e estendendo-se até 138 dias. Constantin (1993), também em condições de infestação com capim-braquiária, mas na época das chuvas, obteve PAI de zero a 70 dias e um PTPI de zero a 49 dias, dispensando períodos residuais de controle. Kuva et al. (2000) conduziram outro ensaio na mesma época, porém com infestação de tiririca, e constataram ausência de PCPI, recomendando práticas de controle desprovido de períodos residuais.

Houve correlação negativa entre o acúmulo de matéria seca pelas plantas daninhas e a produção estimada de colmos de canade-açúcar (Figuras 6 e 8). O acúmulo de 3,26 g M.S. nî pela população de capim-braquiária ou de 1,27 g M.S. $\mathrm{m}^{-2}$ pela população de capim-colonião, convivendo com a cana-deaçúcar no início do ciclo (0 - 147 DAP), resultou 


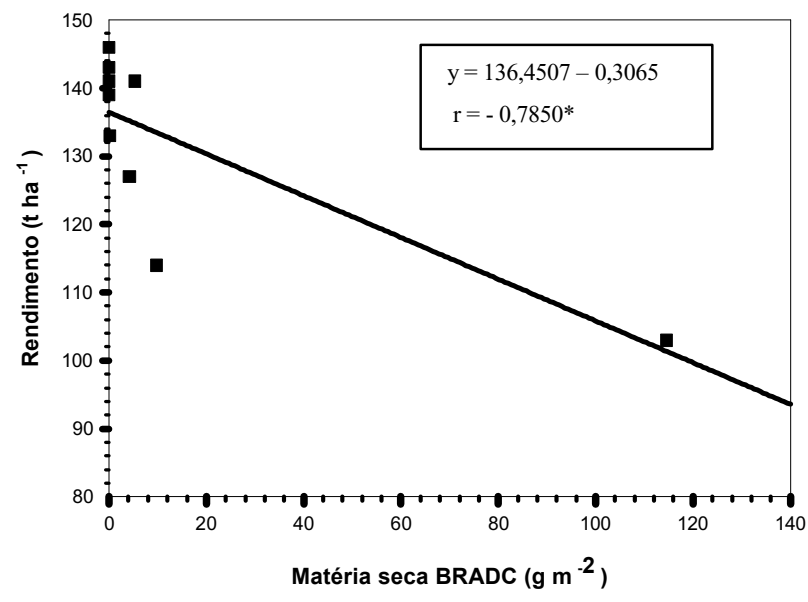

Figura 6 - Estimativa do rendimento de colmos de cana-deaçúcar, para períodos crescentes de convivência, em função da massa de matéria seca de capim-braquiária. São João da Boa Vista-SP, 1995.

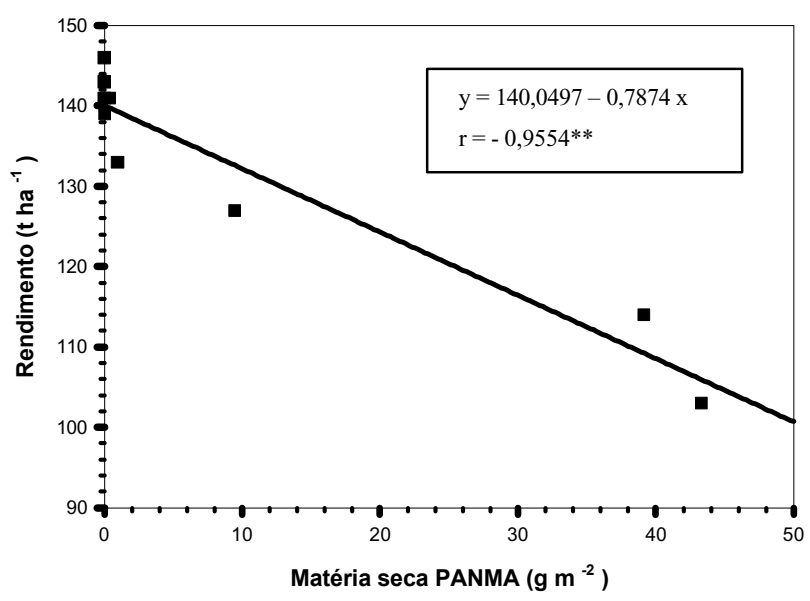

Figura 7 - Estimativa do rendimento de colmos de cana-deaçúcar, para períodos crescentes de convivência, em função da massa de matéria seca de capim-colonião. São João da Boa Vista-SP, 1995.

em reduções de rendimento na ordem de 1 t hat. No entanto, a comunidade infestante total reduziu o rendimento da cana-de-açúcar em $1 \mathrm{t} \mathrm{ha}^{1}$ a cada 26,5 g M.S. $\mathrm{m}^{-2}$ acumulado (Figura 8). Kuva et al. (2001) e Constantin (1993) também observaram correlação negativa entre a produção de massa de capimbraquiária e a produção de cana-de-açúcar. Em função dos períodos crescentes de convivência inicial, Kuva et al. (2001) concluíram que a cada $3,70 \mathrm{~g} \mathrm{~m}^{-2}$ de matéria seca acumulada pelo capim-braquiária havia uma estimativa de redução na produtividade da cana-de-açúcar da ordem de $1 \mathrm{t} \mathrm{ha}^{-1}$.

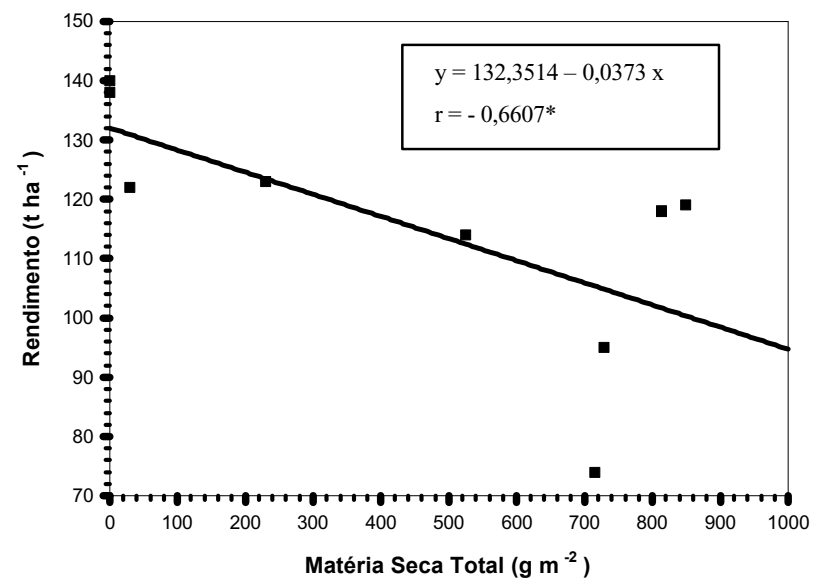

Figura 8 - Estimativa do rendimento de colmos de cana-deaçúcar, para períodos crescentes de controle, em função da massa de matéria seca da comunidade infestante. São João da Boa Vista-SP, 1995.

\section{LITERATURA CITADA}

BIANCO, S. et al. Produção de matéria seca e marcha de absorção de macronutrientes por plantas de capimbraquiária. In: CONGRESSO BRASILEIRO DA CIÊNCIA DAS PLANTAS DANINHAS, 22., 2000, Foz do Iguaçu. Anais... Foz do Iguaçu: SBCPD, 2000. p. 61.

BOZÁN, J. I. R.; REY, H. A. Métodos para el conteo de semillas de malas hierbas en el solo. R. Centr. Agric., v. 4, n. 2, p. 79-89, 1977.

COLETI, J. T. et al. Brachiaria pode provocar sérios danos nos canaviais. Inf. Coopercitrus, n. 132, p. 34-35, 1997.

CONSTANTIN, J. Efeitos de diferentes períodos de controle e convivência da Brachiaria decumbens Stapf. com a cana-de-açúcar (Saccharum spp.). 1993. 98 f. Dissertação (Mestrado em Agronomia) - Universidade Estadual Paulista, Botucatu, 1993.

GRACIANO, P. A. Interferência e manejo de plantas daninhas em áreas de cana-de-açúcar (Saccharum spp.) intercalada com feijões (Phaseolus vulgaris e Vigna unguiculata L. Walp.). 1989. 184 f. Dissertação (Mestrado em Fitotecnia) - Escola Superior de Agricultura "Luiz de Queiroz", Piracicaba, 1989.

GRACIANO, P. A.; RAMALHO, J. F. G. P. Efeito da matocompetição na cultura da cana-de-açúcar. STAB, v. 1, n. 5 , p. 22-24, 1983.

GRACIANO, P. A.; BARBOSA, G. V. S. Efeitos da matocompetição sobre a cultura da cana-de-açúcar variedade Co 997. In: CONGRESSO BRASILEIRO DE HERBICIDAS E PLANTAS DANINHAS, 16., 1986, Campo Grande. Anais... Campo Grande: SBHDE, 1986. p. 16.

Planta Daninha, Viçosa-MG, v.21, n.1, p.37-44, 2003 
KUVA, M. A. et al. Períodos de interferência das plantas daninhas na cultura da cana-de-açúcar. I - Tiririca. Planta Daninha, v. 18, n. 2, p. 241-251, 2000.

KUVA, M. A. et al. Períodos de interferência das plantas daninhas na cultura da cana-de-açúcar. II - Capim-

Braquiária (Brachiaria decumbens). Planta Daninha, v. 19, n. 3, p. 323-330, 2001

LORENZI, H. Plantas daninhas e seu controle na cultura da cana-de-açúcar. In: SEMINÁRIO DE TECNOLOGIA AGRONÔMICA, 4., 1988, Piracicaba. Anais... São Paulo: COOPERSUCAR, 1988. p. 281-301.
PELLEGRINI, M. T. Interferência inter e intra-específica de Brachiária decumbens, Panicum maximum e Eucaliptus grandis por macronutrientes. 2000. $76 \mathrm{f}$. (Trabalho de graduação Agronomia) - Universidade Estadual Paulista, Jaboticabal, 2000 .

PITELLI, R. A. Interferência de plantas daninhas em culturas agrícolas. Inf. Agropec., v. 11, n. 129, p. 16-27, 1985.

ROLIM, J. C.; CHRISTOFFOLETI, P. J. Período crítico de competição de plantas daninhas com cana planta de ano. Saccharum APC, v. 5, n. 22, p. 21-26, 1982. 